\title{
Commentary
}

\section{Empowering Users to Respond to Misinformation about Covid-19}

\author{
Emily K. Vraga ${ }^{1, *}$, Melissa Tully ${ }^{2}$ and Leticia Bode ${ }^{3}$ \\ ${ }^{1}$ Hubbard School of Journalism and Mass Communication, University of Minnesota, Minneapolis, MN 55455, USA; \\ E-Mail: ekvraga@umn.edu \\ 2 School of Journalism and Mass Communication, University of lowa, lowa City, IA 52242, USA; \\ E-Mail: melissa-tully@uiowa.edu \\ ${ }^{3}$ Communication, Culture, and Technology, Georgetown University, Washington, DC 20057, USA; \\ E-Mail: Ib871@georgetown.edu \\ * Corresponding author
}

Submitted: 28 April 2020 | Accepted: 8 May 2020 | Published: 26 June 2020

\begin{abstract}
The World Health Organization has declared that misinformation shared on social media about Covid-19 is an "infodemic" that must be fought alongside the pandemic itself. We reflect on how news literacy and science literacy can provide a foundation to combat misinformation about Covid-19 by giving social media users the tools to identify, consume, and share high-quality information. These skills can be put into practice to combat the infodemic by amplifying quality information and actively correcting misinformation seen on social media. We conclude by considering the extent to which what we know about these literacies and related behaviors can be extended to less-researched areas like the Global South.
\end{abstract}

\section{Keywords}

Coronavirus; correction; Covid-19; misinformation; news literacy; social media

\section{Issue}

This commentary is part of the issue "Health and Science Controversies in the Digital World: News, Mis/Disinformation and Public Engagement" edited by An Nguyen (Bournemouth University, UK) and Daniel Catalan (University Carlos III of Madrid, Spain).

(C) 2020 by the authors; licensee Cogitatio (Lisbon, Portugal). This article is licensed under a Creative Commons Attribution 4.0 International License (CC BY).

\section{Introduction}

Social media are often blamed for spreading misinformation. During the Covid-19 pandemic, the World Health Organization (WHO) raised concerns about an "infodemic" (WHO, 2020), as social media amplify and exacerbate the spread of misinformation and uncertainty that has long surrounded emerging health issues (Dalrymple, Young, \& Tully, 2016; Zarocostas, 2020).

Misinformation on social media is a problem that must be taken seriously in the case of Covid-19. Misinformation circulates surrounding the origins of the virus, how it spreads, and how to cure it (Brennen, Simon, Howard, \& Nielsen, 2020), which could deter effective preventative behaviors. For example, misinformation about chloroquine as a "cure" for Covid-19 has resulted in negative health outcomes including death (Lovelace, 2020).

At the same time, the Covid-19 pandemic represents a novel context in which to consider how to mitigate misinformation. The voracious public appetite for news (Jurkowitz \& Mitchell, 2020b; Koeze \& Popper, 2020) creates an opportunity to leverage this interest into longlasting, effective information consumption habits that could serve as a grounding for online behaviors.

Building news literacy and science literacy provide a foundation to improve information consumption processes by giving social media users the tools to identify, consume, and share high-quality information regarding Covid-19. With these tools, users can expand the reach of expert organizations and correct misinformation on the virus as it spreads. 


\section{Bolstering News and Science Literacy}

Growing concerns about misinformation have sparked a reemergence of interest in how news literacy might help audiences make informed information decisions (Mantas, 2020). News literacy is defined as 'knowledge of the personal and social processes by which news is produced, distributed, and consumed, and skills that allow users some control over these processes' (Vraga, Tully, Maksl, Craft, \& Ashley, in press), and must be developed in combination with a sense of efficacy, social norms about the value of news literacy, and positive attitudes towards the application of news literacy.

Applying news literacy provides one solution to help people manage social media environments, where good and bad information comingle (Vosoughi, Roy, \& Aral, 2018). Social media information surrounding Covid-19 exemplifies this: One study found that $48 \%$ of Americans said they have seen at least some made-up news about Covid-19, and this percentage was highest among those who say social media was the most common way they get news (Jurkowitz \& Mitchell, 2020a; Schaeffer, 2020).

Previous research has suggested that familiarity with news routines and experience with news literacy helps audiences identify misinformation (Amazeen \& Bucy, 2019; Kahne \& Bowyer, 2017) and reduce their acceptance of conspiracy theories (Craft, Ashley, \& Maksl, 2017). Likewise, news literacy and valuing news literacy are associated with more skepticism of information on social media (Vraga \& Tully, 2019). Therefore, a background in news literacy may also help people identify misinformation regarding Covid-19.

Given the emergent nature of the crisis, however, we must consider what can be done to boost news literacy and its application to information about Covid-19 right now. Even those high in news literacy may not apply their knowledge and skills to the difficult task of differentiating high-quality from low-quality information (Tully, Vraga, \& Smithson, 2018; Vraga et al., in press). Therefore, interventions that translate news literacy into behaviors that shape information consumption surrounding Covid-19 should be prioritized.

This translation is not necessarily easy. Our recent research shows that a tweet offering tips for identifying misinformation (such as double-checking the source, being aware of your reaction, and watching for red flags) led people to rate a false news story about the flu vaccine as less credible (Tully, Vraga, \& Bode, 2020). Notably, however, that message did not make people more receptive to expert correction on the topic, which is often connected to reduced misperceptions (Vraga, Bode, \& Tully, 2020). Other news literacy messages that reminded people about biases in news and personal interpretations were ineffective for recognition of misinformation and reception of expert correction (Tully et al., 2020; Vraga et al., 2020).

This research provides concrete suggestions for news literacy efforts on social media. First, news literacy mes- saging should offer concrete recommendations regarding misinformation and its characteristics, rather than general messages about information processing. Second, invoking injunctive and descriptive norms about what people should be or are already doing in terms of critical information processing may help people see sharing high-quality information as both normal and important (Cialdini et al., 2006; Vraga et al., in press). Third, frequent posting of news literacy messages may be necessary to have an impact, as our previous research found that news literacy messages often went unnoticed (Tully et al., 2020). In addition, repeated messages can build on each other and address distinct strategies and behaviors.

As one example, the News Literacy Project's (2020) "sanitize before you share" posts, which offer four concrete steps to stop the spread of misinformation on Covid-19, meet many of these criteria. Likewise, National Public Radio released a cartoon sharing tips for identifying and responding to misinformation that may prove not only informative but engaging (Jin \& Parks, 2020). These types of messages should be shared frequently and widely to boost their impact, and may be improved by invoking normative beliefs about the value of news literacy.

Messages that focus on scientific or health literacy could further the utility of news literacy efforts. Public knowledge regarding the scientific process is generally low, which can be problematic in the context of a rapidly evolving pandemic like Covid-19. For example, a 2019 Pew research study (Kennedy \& Hefferon, 2019) found that $76 \%$ of Americans can define an incubation period, $67 \%$ understand that science is an iterative process, and $60 \%$ are aware of the importance of a control group in determining drug effectiveness. This knowledge is directly relevant to Covid-19, as efforts to mitigate the spread of the disease are tied to the relatively long incubation period, and promising new drugs require clinical trials with control groups. Helping the public understand the scientific process may facilitate acceptance of evolving recommendations like the use of face masks to prevent the spread of Covid-19, without undermining trust in scientists and health professionals.

\section{Empowering Users}

With a stronger foundation in understanding news, science, and health domains, users may not just be more critical consumers of information on Covid-19, but emboldened to improve the information environment for everyone. One study of UK news sharers found that many more people had shared content they later found out was misinformation on social media (that is, had shared it thinking it was true) than those who knowingly shared misinformation (Chadwick, Vaccari, \& O'Loughlin, 2018). If much of the misinformation circulating on social media is shared unwittingly, news and scientific literacy that helps people distinguish between good and bad informa- 
tion on Covid-19 could reduce the amount of misinformation shared.

Another way that news and scientific literacy may be acted upon is through more active curation of social media feeds that contain high-quality information to be shared. The American public broadly approves of the job of public health officials during the Covid-19 outbreak (Funk, 2020) and holds favorable views of the Centers for Disease Control and Prevention (CDC) and the Department of Health and Human Services (Pew, 2020). If news literacy behaviors involve not just consuming but sharing accurate news, these positive views of experts may translate into people sharing expert content about Covid-19 on their own feeds, broadening the reach of this content.

News literacy advocates may also encourage users to correct Covid-19 misinformation they see on social media as an extension of their news literacy knowledge and skills. The "sanitize before you share" post from the News Literacy Project could expand that sanitizing behavior to include correcting others; the NPR cartoon already offers that suggestion. Experimental studies demonstrate that user corrections of health misinformation about a range of controversial and emerging health issues reduce misperceptions among the community seeing that interaction (Bode \& Vraga, 2018; Vraga \& Bode, 2017). Now is an ideal time to encourage and facilitate this user correction.

\section{A Global Response}

Just as the pandemic is a global problem that requires a global response, so, too, should efforts to bolster science and news literacy and to reduce misinformation around Covid-19 be global. However, current research is not evenly distributed. An April 2020 compilation of public opinion polls reflects the discrepancy in data about public understanding of the virus-accounting for 147 polls, 29 were conducted in the United States, 23 in the UK, and 12 in China, with far fewer in the rest of the world (Gilani Research Foundation, 2020). Although not an exhaustive list, this account provides a snapshot of the limited data about Covid-19 from the Global South and even from many parts of Europe.

Similarly, we have limited research on news literacy outside of the Global North. One notable study found that news literacy varies widely across countries and that literacy matters for how people use social media for news and information (Newman, Fletcher, Kalogeropoulos, Levy, \& Nielsen, 2018). Designing interventions and messages that address the core tenets of news literacy and are also adaptable to distinct contexts is a challenge that researchers and practitioners must address as a means of equipping audiences with the knowledge and skills they need to engage with Covid-19 information (Vraga et al., in press). For example, in many countries, WhatsApp is a popular source of information and connection, making it fertile ground for the spread of misinformation (Resende et al., 2019). Developing news literacy interventions for WhatsApp and similar apps represents both a challenge and opportunity as both misinformation and correction are likely to be more trusted when originating from close ties (Margolin, Hannak, \& Weber, 2018).

More work is needed to understand how well research on science and news literacy translates across contexts. For example, trust in government, health officials and media systems vary widely by country, which affects how information is received and acted upon by citizens (AFP, 2020; Bratton \& Gyimah-Boadi, 2016). Asking people to promote messages about Covid-19 from public health organizations may not be merited or useful in all contexts. Likewise, norms around social media uses and expectations about information dissemination on social media platforms likely vary by country, culture, and context (Newman et al., 2018).

\section{Conclusion}

In many ways, Covid-19 represents a novel pandemic, in terms of its spread and impact on the global economy as well as the media environment in which people learn about the virus and its effects. But we can build from existing research to improve how we respond to misinformation about the virus. Fostering news and science literacy provides a flexible solution that can help people distinguish quality information about Covid-19 and empower more active curation of their social media feeds to protect themselves and others from misinformation. To be effective, we must consider global implementation, starting with an improved understanding of diverse contexts and existing science and news literacy to develop appropriate interventions.

\section{Conflict of Interests}

The authors declare no conflict of interests.

\section{References}

AFP. (2020, March 26). Public distrust hampers Africa fight against virus misinformation. Standard Digital. Retrieved from https://www.standardmedia.co.ke/ article/2001365810/public-distrust-hampers-africafight-against-virus-misinformation

Amazeen, M. A., \& Bucy, E. P. (2019). Conferring resistance to digital disinformation: The inoculating influence of procedural news knowledge. Journal of Broadcasting \& Electronic Media, 63, 415-432.

Bode, L., \& Vraga, E. K. (2018). See something, say something: Correction of global health misinformation on social media. Health Communication, 33, 1131-1140.

Bratton, M., \& Gyimah-Boadi, E. (2016). Do trustworthy institutions matter for development? Corruption, trust, and government performance in Africa (Afro- 
barometer Dispatch No. 112). Retrieved from https:// afrobarometer.org/sites/default/files/publications/ Dispatches/ab_r6_dispatchno112_trustworthy_ institutions_and_development_in_africa.pdf

Brennen, J. S., Simon, F. M., Howard, P. N., \& Nielsen, R. K. (2020). Types, sources, and claims of Covid-19 misinformation. Reuters Institute. Retrieved from https://reutersinstitute.politics.ox.ac.uk/typessources-and-claims-Covid-19-misinformation

Chadwick, A., Vaccari, C., \& O'Loughlin, B. (2018). Do tabloids poison the well of social media? Explaining democratically dysfunctional news sharing. New $\mathrm{Me}$ dia \& Society, 20, 4255-4274.

Cialdini, R. B., Demaine, L. J., Sagarin, B. J., Barrett, D. W., Rhoads, K., \& Winter, P. L. (2006). Managing social norms for persuasive impact. Social Influence, 1, 3-15.

Craft, S., Ashley, S., \& Maksl, A. (2017). News media literacy and conspiracy theory endorsement. Communication and the Public, 2, 388-401.

Dalrymple, K. E., Young, R., \& Tully, M. (2016). “Facts, not fear": Negotiating uncertainty on social media during the 2014 Ebola crisis. Science Communication, 38, 442-467.

Funk, C. (2020). Polling shows signs of public trust in institutions amid the pandemic. Pew Research Center. Retrieved from https://www.pewresearch.org/ science/2020/04/07/polling-shows-signs-of-publictrust-in-institutions-amid-pandemic

Gilani Research Foundation. (2020). One window access to polls on Covid-19 from across the world during first quarter of 2020. Gilani Research Foundation. Retrieved from http://gilani-gallopedia.org/Covid-19_ Polls_Compilation.pdf

Jin, C. H., \& Parks, M. (2020, April 20). Comic: Fake news can be deadly. Here's how to spot it. National Public Radio. Retrieved from https://www.npr.org/2020/ 04/17/837202898/comic-fake-news-can-be-deadlyheres-how-to-spot-it

Jurkowitz, M., \& Mitchell, A. (2020a). Americans who primarily get news through social media are least likely to follow Covid-19 coverage, most likely to report seeing made-up news. Pew Research Center. Retrieved from https://www.journalism.org/2020/ 03/25/americans-who-primarily-get-news-throughsocial-media-are-least-likely-to-follow-Covid-19coverage-most-likely-to-report-seeing-made-upnews

Jurkowitz, M., \& Mitchell, A. (2020b). Older Americans continue to follow Covid-19 news more closely than younger adults. Pew Research Center. Retrieved from https://www.journalism.org/2020/04/22/olderamericans-continue-to-follow-Covid-19-news-moreclosely-than-younger-adults

Kahne, J., \& Bowyer, B. (2017). Educating for democracy in a partisan age: Confronting the challenges of motivated reasoning and misinformation. American $E d$ ucational Research Journal, 54(1), 3-34.
Kennedy, B., \& Hefferon, M. (2019). What Americans know about science. Pew Research Center. Retrieved from https://www.pewresearch.org/science/2019/ 03/28/what-americans-know-about-science

Koeze, E., \& Popper, N. (2020, April 7). The virus changed the way we Internet. The New York Times. Retrieved from https://www.nytimes.com/interactive/2020/ 04/07/technology/coronavirus-internet-use.html

Lovelace, B. (2020, April 24). FDA issues warnings on chloroquine and hydroxychloroquine after deaths and poisonings reported. CNBC. Retrieved from https://www.cnbc.com/2020/04/24/fda-issueswarnings-on-chloroquine-and-hydroxychloroquineafter-serious-poisoning-and-death-reported.html

Mantas, H. (2020, April 13). Fact-checkers spread the gospel of media literacy amid the Covid-19 crisis. Poynter. Retrieved from https://www.poynter.org/ fact-checking/2020/fact-checkers-spread-thegospel-of-media-literacy-amid-the-Covid-19-crisis

Margolin, D. B., Hannak, A., \& Weber, I. (2018). Political fact-checking on Twitter: When do corrections have an effect? Political Communication, 35, 196-219.

Newman, N. R., Fletcher, R., Kalogeropoulos, A., Levy, D. A. L., \& Nielsen, R. K. (2018). Reuters Institute digital news report 2018. Retrieved from http:// media.digitalnewsreport.org/wp-content/uploads/ 2018/06/digital-news-report-2018.pdf

News Literacy Project. (2020). Practice good information hygiene: Sanitize before you share. News Literacy Project. Retrieved from https://newslit.org/ get-smart/information-hygiene-sanitize-before-youshare

Pew. (2020, April 9). Public holds broadly favorable views of many federal agencies, including CDC and HHS. Pew Research Center. Retrieved from https://www.people-press.org/2020/04/09/publicholds-broadly-favorable-views-of-many-federalagencies-including-cdc-and-hhs

Resende, G., Melo, P., Sousa, H., Messias, J., Vasconcelos, M., Almeida, J., \& Benevenuto, F. (2019). (Mis)Information dissemination in WhatsApp: Gathering, analyzing and countermeasures. In The World Wide Web Conference (pp. 818-828). Sunnyvale, CA: Web4Good.

Schaeffer, K. (2020). Nearly three-in-ten Americans believe Covid-19 was made in a lab. Pew Research Center. Retrieved from https://www.pewresearch.org/ fact-tank/2020/04/08/nearly-three-in-tenamericans-believe-Covid-19-was-made-in-a-lab

Tully, M., Vraga, E. K., \& Bode, L. (2020). Designing and testing news literacy interventions for social media. Mass Communication and Society, 23, 22-46.

Tully, M., Vraga, E. K., \& Smithson, A. (2018). News media literacy, perceptions of bias, and interpretation of news. Journalism, 21, 209-226.

Vosoughi, S., Roy, D., \& Aral, S. (2018). The spread of true and false news online. Science, 359, 1146-1151.

Vraga, E. K., \& Bode, L. (2017). Using expert sources to 
correct health misinformation in social media. Science Communication, 39, 621-645.

Vraga, E. K., Bode, L., \& Tully, M. (2020). Creating news literacy messages to enhance expert corrections of misinformation on Twitter. Communication Research. Advance online publication. https://doi.org/10.1177\%2F0093650219898094

Vraga, E. K., \& Tully, M. (2019). News literacy, social media behaviors, and skepticism toward information on social media. Information, Communication \& Society. https://doi.org/10.1080/1369118X.2019.1637445
Vraga, E. K., Tully, M., Maksl, A., Craft, S., \& Ashley, S. (in press). Theorizing news literacy behaviors. Communication Theory.

World Health Organization. (2020). Infodemic management: Infodemiology. World Health Organization. Retrieved from https://www.who.int/teams/ risk-communication/infodemic-management

Zarocostas, J. (2020). How to fight an infodemic. The Lancet, 395(10225). https://doi.org/10.1016/S01406736(20)30461-X

\section{About the Authors}

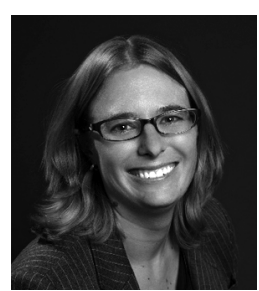

Emily K. Vraga is an Associate Professor at the Hubbard School of Journalism and Mass Communication at the University of Minnesota, where she holds the Don and Carole Larson Professorship in Health Communication. Her research tests methods to identify and correct health misinformation on social media, to limit biased processing using news literacy messages, and to encourage attention to more diverse content online.

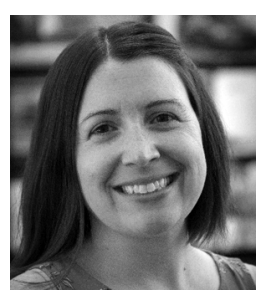

Melissa Tully is an Associate Professor in the School of Journalism and Mass Communication at the University of lowa. Her research interests include news literacy, misinformation, civic and political participation, and global media studies. She conducts research in the United States and East Africa, mostly in Kenya.

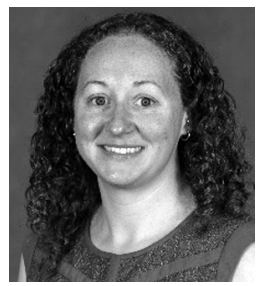

Leticia Bode is a Provost's Distinguished Associate Professor in the Communication, Culture, and Technology master's program at Georgetown University. She researches the intersection of communication, technology, and political behavior, emphasizing the role communication and information technologies may play in the acquisition, use, effects, and implications of political information and misinformation. 